Radiol Clin North Am. 2008 July ; 46(4): 643-v. doi:10.1016/j.rcl.2008.07.005.

\title{
Epidemiology of Aging
}

\author{
Luigi Ferrucci, MD, PhD ${ }^{a},{ }^{*}$, Francesco Giallauria, MD,PhD ${ }^{a}$, and Jack M. Guralnik, MD, \\ PhD
}

aLongitudinal Studies Section, Clinical Research Branch, National Institute on Aging, National Institutes of Health, MD, USA

bLaboratory of Epidemiology, Demography, and Biometry, National Institute on Aging, National Institutes of Health, MSC 9205, 7201 Wisconsin Avenue, Bethesda, MD 20892-9205, USA

\section{Keywords}

Aging; Epidemiology; Demographics; Mortality; Disability; Risk factors

Over the past century, truly remarkable changes have been observed in the health of older persons throughout the world, and these changes have strongly impacted society. The growth of the older population has resulted mostly from a general increase in the overall population size but is also strongly influenced by major declines in leading causes of mortality. These demographic transformations reverberate in society, increasing medical care and social needs, which are expected to increase steeply in the years to come. ${ }^{1}$ Based on demographic and epidemiologic perspectives, these changes were already detectable decades before and should have prompted radical changes in the structure and function of our system of health and social protection at that time. We come to this enormous challenge unprepared.

As more people live to advanced old age, these demographic changes imply much more than just an increase in chronic morbidity. The same agerelated susceptibility that leads to the occurrence of multiple chronic conditions in the same individual causes decrements in functional abilities as well as social and psychologic problems that may have an impact on many facets of their wellbeing and quality of life. Going beyond the demographic focus of counting and projecting the number of older people in the population, epidemiology has made additional contributions to our understanding of the health status and functional trajectory of older individuals. $^{2-6}$

Geriatric epidemiology approaches these challenges by studying the health, functional status, and quality of life of representative populations of individuals, ideally throughout the entire life span. The results of these population-based studies have often generated interventions aimed at improving the life of millions of older individuals.

\section{DEMOGRAPHICS}

Population aging is taking place throughout the world (Fig. 1). In 1900 only $4.1 \%$ of the 76 million persons in the United States were aged 65 years and older, and among those in this age group only $3.2 \%$ were aged 85 years and older. By 1950 more than $8 \%$ of the total population was aged 65 years and older, and by 2000 this percentage had increased to $12.6 \%$ (Table 1). 
Change in the proportion of a population that is elderly depends on changes in the survival of older persons and in the birthrate. Improved survival at older ages and a low birthrate have resulted in European countries having the oldest populations in the world. Italy and Germany are estimated to have the oldest populations in Europe and the second and third oldest in the world at approximately $19 \%$ each. Europe will continue to have the oldest populations in the world in the twenty-first century, with almost one in four Europeans projected to be aged 65 years or older by $2030 .^{7}$

Populations have aged at different speeds in different countries, with less ability to adapt than in countries that have aged more slowly. Better survival at all ages has had a major impact on the size and age distribution of the older population, but its effect on the life of individuals is modulated by parallel changes in health status (Fig. 2). The change observed in the shape of survival curves, which has been termed rectangularization, shows that more and more individuals survive to very old age, and all of them die in a very narrow time window. It has been proposed that this "compression" is due the fact that, as human life approaches its absolute biologic limits, improvements in health will contribute mostly to a reduction of morbidity but very little to further increases in life expectancy. 8

It seems crucial to examine changes in life expectancy over the last century and life expectancy at specific ages. Life expectancy at birth was only 47.3 years in 1900 and rose to 68.2 years by 1950 , affected to a large extent by improvements in infant and child mortality. Life expectancy continued to rise through the second half of the twentieth century, driven mainly by increases in survival in middle and old age.

The improvements in survival over the last century are relevant to the field of geriatric medicine. The decline in mortality rates throughout life has resulted in a population with a large proportion of individuals who survive to advanced old age. Interestingly, many of the medical interventions used in these progressively older patients were originally tested in much younger individuals; therefore, their effectiveness and safety are little understood. Although there has always been a fascination with extreme longevity, the demographics of a very long life have been formally studied only in recent years. Studying centenarians provides a magnified view of the aging process and suggests that factors that affect a decline in health status, disability, and mortality in individuals in their nineties are quite different from those identified in younger individuals. ${ }^{9-12}$

Previous reports of longevity were often unsubstantiated, and pockets of the world where claims were made for general high longevity usually turned out to be no different from other parts of the world. Nevertheless, recent data from places such as Sardinia, Italy, have identified areas of increased longevity that have been meticulously validated. ${ }^{13-16}$ There is currently no solid evidence explaining why centenarians are concentrated in these geographic areas.

Although family and twin studies suggest a strong genetic predisposition to extreme longevity and candidate genes have been described, the full mechanism is not understood. The secret is probably a lucky combination of favorable genetic background and environmental factors that exert their influence in critical periods over the life span. In fact, many centenarians report that they were completely independent in self-care activities of daily living and free of disabling conditions up to their late nineties. In addition, a sizable proportion of centenarian "escapers" are totally independent and free of major medical conditions. ${ }^{17-24}$

\section{MORTALITY}

The increasingly greater life expectancy of the population has been driven in part by reduced mortality at older ages (Table 2). ${ }^{8}$ As is true in younger individuals, heart disease is by far the most common cause of death, followed by cancer. The five leading causes of death-heart disease, cancer, stroke, chronic lower respiratory tract disease, and Alzheimer's disease- 
account for $69.5 \%$ of all deaths. Alzheimer's disease, only recently included on the list of leading causes of death, was the seventh leading cause of death in older persons in 2000 and in 2003 rose to the fifth leading cause of death. This ranking is still likely a gross underestimation, and the contribution of Alzheimer's disease in the future will probably grow substantially.

Age-specific mortality rates for selected leading causes of death are depicted in Table 2 . On this logarithmic scale a straight-line increase indicates an exponential increase in mortality rate with age. An exponential increase is present for all causes of death, and parallel increases are seen for heart disease, cerebrovascular disease, pneumonia, and influenza. The exponential rise with age for Alzheimer's disease mortality is substantially steeper. The mortality rates for cancer and lower respiratory tract disease do not maintain as steep a rise with increasing age, perhaps because the people who contribute in large part to these categories are smokers who die at younger ages and are less represented in the oldest segment of the population. Diabetes mortality rates also do not show an exponential increase with advancing age, again because diabetic patients may die disproportionately at younger ages.

The first half of the twentieth century saw large declines in infant and child mortality, whereas in the second half of the century unprecedented declines in mortality occurred in the older segment of the population. Mortality change over this time period is further explored in Table 3 , which lists 1950 and 2004 death rates and the percentage changes in these rates for heart disease, stroke, and cancer, diseases that account for $60 \%$ of deaths in older adults. ${ }^{25}$ The total population and a subgroup of individuals aged more than 85 years showed a truly remarkable decline in heart disease and stroke, reflecting major advances in prevention and treatment as well as a secular trend that is not fully understood. Unfortunately, the mortality rate seen for cancer does not have the same trend.

\section{DISEASE STATUS}

Although there is much useful information to be gained by observing the diseases responsible for mortality, a full picture of disease status in the older population cannot be obtained by looking only at diseases that cause death. Among people aged 65 years and older in the United States, the most commonly reported condition is hypertension, followed by coronary heart disease and stroke. Arthritis and chronic joint symptoms are reported by a large proportion of older persons, and these conditions, like many on the list, have a large impact on overall health and quality of life but do not appear on the list of the most common conditions causing death (Table 4). ${ }^{26}$ Moreover, some differences occur in the prevalence rates of chronic conditions according to race and ethnicity. 26

An important aspect of disease status that distinguishes the older population from the younger population is the high rate of co-occurrence of multiple chronic conditions, termed comorbidity. The concept of comorbidity is useful in considering the burden of disease in older people; however, the standardization of a definition for comorbidity depends on the number of conditions being ascertained and the intensity of the diagnostic effort to identify prevalent diseases. The longer the list of conditions and the harder one works to find prevalent diseases, the greater the prevalence of comorbidity.

According to the National Hospital Discharge Survey, heart disease is by far the most important cause of hospitalization, with congestive heart failure a slightly more common cause of hospitalization than other manifestations of heart disease (Table 5). ${ }^{27}$ Other diseases that are frequent causes of death in older adults (pneumonia, stroke, and cancer) are also common reasons for hospitalization, but so are diseases not as strongly associated with mortality, including fractures, osteoarthritis, chronic bronchitis, and psychosis. Of note, the presence of 
septicemia and volume depletion reflects the fact that a portion of the older population is frail and at high risk for these types of illnesses. ${ }^{27}$

Cancer mortality rates do not always reflect the incidence rates of newly diagnosed cancers. 28-33 Data from the Surveillance, Epidemiology and End Results (SEER) survey of the National Cancer Institute and other cancer registries show that the highest incidence rates in men are seen for prostate, lung, colon and rectum, and bladder cancers and in women for breast, colon and rectum, lung, and uterine cancers. The incidence of most of these cancers rises steadily with increasing age, but several types, including prostate, breast, and lung cancers, begin to drop in incidence at the oldest ages. 34,35

Dementia is a condition of aging for which prevalence and incidence rates cannot be validly obtained from either national survey data or registries. Because of the complexities of diagnosing dementia, data on the occurrence of the condition must rely on well-designed epidemiologic studies in local geographic areas. An even larger collection of studies on dementia incidence from around the world supports an exponential increase in dementia with age and demonstrates that rates tend to be lower in East Asia than in Europe and the United States. $4,36-44$

\section{DISABILITY}

A large body of epidemiologic studies undertaken over the past 2 decades has led to a greater understanding of the occurrence, determinants, and consequences of disability in the older population and has provided insights into strategies for the prevention of disability. ${ }^{45-54}$ Measures of disability were originally developed for use in the clinical setting and were aimed at quantifying the impact of severe medical conditions such as stroke on physical and mental functioning, obtaining standard information on the rate and degree of recovery from these conditions and assessing work ability and the need for formal and informal care. These assessment tools were gradually applied in clinical research and population-based studies, and almost all research studies in older populations now assess disability status.

Physical limitations include basic tasks such as standing, reaching, and grasping. These tasks represent the building blocks of functioning but are not specific measures of disability. Activities of daily living (ADLs) are basic self-care tasks. Instrumental ADL (IADLs) are tasks that are physically and cognitively somewhat more complicated and difficult than self-care tasks and are necessary for independent living in the community. ADLs and IADLs are measures of disability and reflect how an individual's limitations interact with the demands of the environment.

Disability has been assessed with a wide variety of instruments, but even when instruments contain the same items, they may differ in how they assess specific aspects of performing the task or the severity of limitation in performing the task. There is no single best way to perform a disability assessment, and there is no single instrument that is ideal. Moreover, the lack of standardization that results from the use of multiple competing instruments makes it difficult to compare rates of disability across studies. ${ }^{45-54}$

Epidemiologic studies have clearly identified disability status to be one of the most powerful markers in predicting adverse outcomes. Disability measures are able to capture the impact of the presence and severity of multiple pathologies, including physical, cognitive, and psychologic conditions, as well as the potential synergistic effects of these conditions on overall health status. ${ }^{45-61}$

Longitudinal studies in older populations have revealed the presence of multiple risk factors for disability, as well as the dynamics of disability onset and progression (Box 1). ${ }^{55-61}$ 
Interestingly, a substantial proportion of individuals who are disabled report improvement on subsequent assessments. In effect, disability is a product of the disease or diseases from which an individual suffers, a sedentary lifestyle or disuse, and physiologic declines that may be the result of aging or pathologic processes that are not specific diseases but result from factors such as inflammation or endocrine changes. As these predisposing conditions change, they have an impact on the initiation of disability and on changes in the status of already established disability.

\section{Box 1}

\section{Risk factors for functional status decline}

Behavioral risk factors and individual characteristics

Low physical activity

Smoking

High and low body mass index, weight loss

Heavy and no alcohol consumption

Increased age

Lower socioeconomic status (income, education)

High medication use

Poor self-rated health

Reduced social contacts

Chronic conditions

Cardiovascular disease

Hypertension

Coronary heart disease

Myocardial infarction

Angina pectoris

Congestive heart failure

Stroke

Intermittent claudication

Osteoarthritis

Hip fracture

Diabetes

Chronic obstructive pulmonary disease

Cancer

Visual impairment

Depression

Cognitive impairment 
In understanding the dynamics of disability progression, it is useful to consider the pace at which disability develops. The terms progressive disability and catastrophic disability have been used, indicating a slow downhill course and a rapid decline, respectively. Progressive disability results from one or more ongoing chronic conditions and causes disability over months or years, whereas catastrophic disability can occur in moments as a result of a stroke or hip fracture. The prevalence of both progressive and catastrophic severe ADL disability, defined as needing help with three or more ADLs, increases with increasing age, although progressive disability prevalence rises faster than catastrophic disability (Fig. 3). Among older persons with severe ADL disability, the proportion who have catastrophic ADL disability is much higher at younger ages, and the proportion who have progressive ADL disability is much higher at older ages (see Fig. 3). A similar age pattern has been found for the onset of severe mobility disability (inability to walk across a room); progressive disability is much more common in people who have three or more chronic conditions.

The dynamics of disability can also be approached by studying the pathologic changes that precede its onset. Most disability results from disease, and different theoretical pathways have been proposed to describe the changes that occur as a person proceeds from disease to disability. The theoretical pathway that has received substantial empirical support in aging research postulates that two intermediate steps, impairment and functional limitation, follow disease and lead to disability. Impairment describes the dysfunction and structural abnormalities in specific body systems that result from pathology. Functional limitation describes restrictions in basic physical and mental actions that result from impairments. Functional limitations are the basic building blocks of functioning, and the interaction of these components of functioning with the environmental demands faced by an individual determines whether that person is disabled. 62

Objective measures of physical performance have received increased attention as assessments that can measure functioning in a standardized manner in research and clinical settings. These measures can be used to represent impairments or actual disability, but most are indicators of functional limitations. ${ }^{63}$ Objective performance measures also provide a means of comparing functional status over time or across countries or cultures, whereas disability measures may lose comparability because of environmental differences or differential access to assistive devices.

Because disability status is a good way of representing overall health status in older persons with complex patterns of disease, and because disability also has direct implications for the long-term care needs of an older person, there has been much interest in evaluating disability trends over time. The National Long-Term Care Survey performed similar assessments of ADL and IADL disability from 1982 through 2005. The recent findings indicate that the decline in disability observed for the first 12 years of the study continued and actually accelerated from 1994 through 2005.64

There is interplay among the time of disability onset, the duration of disability, and the time of death that determines the number of years that older individuals live in the disability-free state, termed active life expectancy, and the number of years spent in the disabled state. As more data become available to estimate both active and disabled life expectancy, we will gain more insight into the prospects for a compression of morbidity, which is the reduction in disabled life expectancy that results from compressing chronic disease and disability into a smaller number of years between diseases or disability onset and mortality. 65 


\section{SUMMARY}

An important role for epidemiology is to elucidate risk factors for disease, injury, and disability, and many risk factors have been shown to have a large impact in older persons. Although certain risk factors that are potent predictors of major disease in middle age may have less or no impact at old age, most behavioral risk factors continue to be important throughout old age. Applying what has been learned in epidemiologic studies on older populations so that effective prevention and treatment strategies will be available to older persons is a continuing challenge for the field.

\section{REFERENCES}

1. Lutz W, Sanderson W, Scherbov S. The coming acceleration of global population ageing. Nature 2008;451(7179):716-9. [PubMed: 18204438]

2. Gurven M, Kaplan H, Winking J, et al. Aging and inflammation in two epidemiological worlds. J Gerontol A Biol Sci Med Sci 2008;63(2):196-9. [PubMed: 18314457]

3. Brach JS, Studenski SA, Perera S, et al. Gait variability and the risk of incident mobility disability in community-dwelling older adults. J Gerontol A Biol Sci Med Sci 2007;62(9):983-8. [PubMed: 17895436]

4. Kuller LH. Dementia epidemiology research: it is time to modify the focus of research. J Gerontol A Biol Sci Med Sci 2006;61(12):1314-8. [PubMed: 17234827]

5. Metter EJ, Schrager M, Ferrucci L, et al. Evaluation of movement speed and reaction time as predictors of all-cause mortality in men. J Gerontol A Biol Sci Med Sci 2005;60(7):840-6. [PubMed: 16079205]

6. Metter EJ, Talbot LA, Schrager M, et al. Skeletal muscle strength as a predictor of all-cause mortality in healthy men. J Gerontol A Biol Sci Med Sci 2002;57(10):B359-65. [PubMed: 12242311]

7. Population Division. U.S. Census Bureau. The Census Bureau on prospects for US population growth in the Twenty-First Century. Population and Development Review 2000;26(1):197-200.

8. Miniño AM, Heron M, Smith BL, et al. Deaths: final data for 2004. National Vital Statistics Reports 2007;55(9):1-120.

9. Willcox DC, Willcox BJ, He Q, et al. They really are that old: a validation study of centenarian prevalence in Okinawa. J Gerontol A Biol Sci Med Sci 2008;63(4):338-49. [PubMed: 18426957]

10. Perls T, Kohler IV, Andersen S, et al. Survival of parents and siblings of supercentenarians. J Gerontol A Biol Sci Med Sci 2007;62(9):1028-34. [PubMed: 17895443]

11. Terry DF, Wilcox MA, McCormick MA, et al. Cardiovascular disease delay in centenarian offspring. J Gerontol A Biol Sci Med Sci 2004;59(4):385-9. [PubMed: 15071083]

12. Terry DF, Wilcox M, McCormick MA, et al. Cardiovascular advantages among the offspring of centenarians. J Gerontol A Biol Sci Med Sci 2003;58(5):M425-31. [PubMed: 12730251]

13. Pes GM, Lio D, Carru C, et al. Association between longevity and cytokine gene polymorphisms: a study in Sardinian centenarians. Aging Clin Exp Res 2004;16(3):244-8. [PubMed: 15462469]

14. Caselli G, Pozzi L, Vaupel JW, et al. Family clustering in Sardinian longevity: a genealogical approach. Exp Gerontol 2006;41(8):727-36. [PubMed: 16793232]

15. Poulain M, Pes GM, Grasland C, et al. Identification of a geographic area characterized by extreme longevity in the Sardinia island: the AKEA study. Exp Gerontol 2004;39(9):1423-9. [PubMed: 15489066]

16. Deiana L, Ferrucci L, Pes GM, et al. AKEntAnnos: the Sardinia Study of Extreme Longevity. Aging (Milano) 1999;11(3):142-9. [PubMed: 10476308]

17. Peel NM, McClure RJ, Bartlett HP. Behavioral determinants of healthy aging. Am J Prev Med 2005;28 (3):298-304. [PubMed: 15766620]

18. Karasik D, Demissie S, Cupples LA, et al. Disentangling the genetic determinants of human aging: biological age as an alternative to the use of survival measures. J Gerontol A Biol Sci Med Sci 2005;60 (5):574-87. [PubMed: 15972604]

19. Hadley EC, Rossi WK. Exceptional survival in human populations: National Institute on aging perspectives and programs. Mech Ageing Dev 2005;126(2):231-4. [PubMed: 15621201] 
20. Warner HR. Current status of efforts to measure and modulate the biological rate of aging. J Gerontol A Biol Sci Med Sci 2004;59(7):692-6. [PubMed: 15304533]

21. Olshansky SJ, Hayflick L, Carnes BA. Position statement on human aging. J Gerontol A Biol Sci Med Sci 2002;57(8):B292-7. [PubMed: 12145354]

22. Arking R, Novoseltsev V, Novoseltseva J. The human life span is not that limited: the effect of multiple longevity phenotypes. J Gerontol A Biol Sci Med Sci 2004;59(7):697-704. [PubMed: 15304534]

23. Curb JD, Guralnik JM, LaCroix AZ, et al. Effective aging: meeting the challenge of growing older. J Am Geriatr Soc 1990;38(7):827-8. [PubMed: 2370401]

24. Coppin AK, Ferrucci L, Lauretani F, et al. Low socioeconomic status and disability in old age: evidence from the InChianti study for the mediating role of physiological impairments. J Gerontol A Biol Sci Med Sci 2006;61(1):86-91. [PubMed: 16456198]

25. National Center for Health Statistics. Health, United States, 2006 with chartbook on trends in the health of Americans. Department of Health and Human Services. Centers for Disease Control and Prevention. National Center for Health Statistics; Hyattsville (MD): 2006.

26. Centers for Disease Control and Prevention, National Center for Health Statistics. National Health Interview Survey, sample adult questionnaire: trends in health and aging. [Accessed July 10, 2008]. Available at: http://www.cdc.gov/nchs/agingact.htm

27. Lolak LJ, DeFrances CJ, Hall MJ. National hospital discharge survey: 2004 annual summary with detailed diagnosis and procedure data. National center for health statistics. Vital Health Stat 2006;13 (162):1-218.

28. Blank TO, Bellizzi KM. A gerontologic perspective on cancer and aging. Cancer 2008;112(Suppl 11):2569-76. [PubMed: 18428204]

29. Extermann M, Aapro M. Assessment of the older cancer patient. Hematol Oncol Clin North Am 2000;14(1):63-77. [PubMed: 10680072]

30. Extermann M, Hurria A. Comprehensive geriatric assessment for older patients with cancer. J Clin Oncol 2007;25(14):1824-31. [PubMed: 17488980]

31. Balducci L. Geriatric oncology. Crit Rev Oncol Hematol 2003;46(3):211-20. [PubMed: 12791420]

32. Wells NL, Balducci L. Geriatric oncology: medical and psychosocial perspectives. Cancer Pract 1997;5(2):87-91. [PubMed: 9110644]

33. Balducci L, Extermann M. Cancer and aging: an evolving panorama. Hematol Oncol Clin North Am 2000;14(1):1-16. [PubMed: 10680068]

34. Yabroff KR, Lamont EB, Mariotto A, et al. Cost of care for elderly cancer patients in the United States. J Natl Cancer Inst 2008;100(9):630-41. [PubMed: 18445825]

35. Hayat MJ, Howlader N, Reichman ME, et al. Cancer statistics, trends, and multiple primary cancer analyses from the surveillance, epidemiology, and end results (SEER) program. Oncologist 2007;12 (1):20-37. [PubMed: 17227898]

36. Launer LJ, Andersen K, Dewey ME, et al. Rates and risk factors for dementia and Alzheimer's disease: results from EURODEM pooled analyses. EURODEM Incidence Research Group and Work Groups, European studies of dementia. Neurology 1999;52(1):78-84. [PubMed: 9921852]

37. Obadia Y, Rotily M, Degrand-Guillaud A, et al. The PREMAP study: prevalence and risk factors of dementia and clinically diagnosed Alzheimer's disease in Provence, France. Prevalence of Alzheimer's disease in Provence. Eur J Epidemiol 1997;13(3):247-53. [PubMed: 9258521]

38. Lobo A, Launer LJ, Fratiglioni L, et al. Prevalence of dementia and major subtypes in Europe: a collaborative study of population-based cohorts. Neurologic diseases in the Elderly Research Group. Neurology 2000;54(11 Suppl 5):S4-9. [PubMed: 10854354]

39. Suh GH, Shah A. A review of the epidemiological transition in dementia: cross-national comparisons of the indices related to Alzheimer's disease and vascular dementia. Acta Psychiatr Scand 2001;104 (1):4-11. [PubMed: 11437743]

40. Rice DP, Fillit HM, Max W, et al. Prevalence, costs, and treatment of Alzheimer's disease and related dementia: a managed care perspective. Am J Manag Care 2001;7(8):809-18. [PubMed: 11519239]

41. Chen JH, Chan DC, Kiely DK, et al. Terminal trajectories of functional decline in the long-term care setting. J Gerontol A Biol Sci Med Sci 2007;62(5):531-6. [PubMed: 17522358] 
42. McCarten JR, Hemmy LS, Rottunda SJ, et al. Patient age influences recognition of Alzheimer's disease. J Gerontol A Biol Sci Med Sci 2008;63(6):625-8. [PubMed: 18559638]

43. Dodge HH, Du Y, Saxton JA, et al. Cognitive domains and trajectories of functional independence in nondemented elderly persons. J Gerontol A Biol Sci Med Sci 2006;61(12):1330-7. [PubMed: 17234830]

44. Shibata N, Ohnuma T, Higashi S, et al. Genetic association between Notch4 polymorphisms and Alzheimer's disease in the Japanese population. J Gerontol A Biol Sci Med Sci 2007;62(4):350-1. [PubMed: 17452726]

45. Lauretani F, Semba RD, Bandinelli S, et al. Low plasma carotenoids and skeletal muscle strength decline over 6 years. J Gerontol A Biol Sci Med Sci 2008;63(4):376-83. [PubMed: 18426961]

46. McDermott MM, Tian L, Ferrucci L, et al. Associations between lower extremity ischemia, upper and lower extremity strength, and functional impairment with peripheral arterial disease. J Am Geriatr Soc 2008;56(4):724-9. [PubMed: 18284536]

47. Semba RD, Ferrucci L, Sun K, et al. Oxidative stress and severe walking disability among older women. Am J Med 2007;120(12):1084-9. [PubMed: 18060930]

48. Bandeen-Roche K, Xue QL, Ferrucci L, et al. Phenotype of frailty: characterization in the women's health and aging studies. J Gerontol A Biol Sci Med Sci 2006;61(3):262-6. [PubMed: 16567375]

49. Onder G, Penninx BW, Ferrucci L, et al. Measures of physical performance and risk for progressive and catastrophic disability: results from the Women's Health and Aging Study. J Gerontol A Biol Sci Med Sci 2005;60(1):74-9. [PubMed: 15741286]

50. Chang M, Cohen-Mansfield J, Ferrucci L, et al. Incidence of loss of ability to walk 400 meters in a functionally limited older population. J Am Geriatr Soc 2004;52(12):2094-8. [PubMed: 15571549]

51. Valenti G, Denti L, Maggio M, et al. Effect of DHEAS on skeletal muscle over the life span: the InCHIANTI study. J Gerontol A Biol Sci Med Sci 2004;59(5):466-72. [PubMed: 15123757]

52. Ferrucci L, Penninx BW, Volpato S, et al. Change in muscle strength explains accelerated decline of physical function in older women with high interleukin-6 serum levels. J Am Geriatr Soc 2002;50 (12):1947-54. [PubMed: 12473005]

53. Guralnik JM, Ferrucci L, Balfour JL, et al. Progressive versus catastrophic loss of the ability to walk: implications for the prevention of mobility loss. J Am Geriatr Soc 2001;49(11):1463-70. [PubMed: 11890584]

54. Simonsick EM, Newman AB, Nevitt MC, et al. Measuring higher level physical function in wellfunctioning older adults: expanding familiar approaches in the Health ABC study. J Gerontol A Biol Sci Med Sci 2001;56(10):M644-649. [PubMed: 11584038]

55. Bartali B, Frongillo EA, Guralnik JM, et al. Serum micronutrient concentrations and decline in physical function among older persons. JAMA 2008;299(3):308-15. [PubMed: 18212315]

56. Rantanen T, Guralnik JM, Ferrucci L, et al. Compartments as predictors of severe walking disability in older women. J Am Geriatr Soc 2001;49(1):21-7. [PubMed: 11207838]

57. Penninx BW, Pahor M, Cesari M, et al. Anemia is associated with disability and decreased physical performance and muscle strength in the elderly. J Am Geriatr Soc 2004;52(5):719-24. [PubMed: 15086651]

58. Cesari M, Penninx BW, Pahor M, et al. Inflammatory markers and physical performance in older persons: the InCHIANTI study. J Gerontol A Biol Sci Med Sci 2004;59(3):242-8. [PubMed: 15031308]

59. McDermott MM, Ferrucci L, Simonsick EM, et al. The ankle brachial index and change in lower extremity functioning over time: the Women's Health and Aging Study. J Am Geriatr Soc 2002;50 (2):238-46. [PubMed: 12028204]

60. Taaffe DR, Harris TB, Ferrucci L, et al. Crosssectional and prospective relationships of interleukin-6 and C-reactive protein with physical performance in elderly persons: MacArthur studies of successful aging. J Gerontol A Biol Sci Med Sci 2000;55(12):M709-715. [PubMed: 11129392]

61. Stuck AE, Walthert JM, Nikolaus T, et al. Risk factors for functional status decline in communityliving elderly people: a systematic literature review. Soc Sci Med 1999;48(4):445-9. [PubMed: 10075171]

62. Guralnik JM, Ferrucci L. Assessing the building blocks of function: utilizing measures of functional limitation. Am J Prev Med 2003;25(3 Suppl 2):112-21. [PubMed: 14552934] 
63. Guralnik JM. Assessing the impact of comorbidity in the older population. Ann Epidemiol 1996;6 (5):376-80. [PubMed: 8915467]

64. Manton KG, Gu X, Lamb VL. Change in chronic disability from 1982 to 2004/2005 as measured by long-term changes in function and health in the US elderly population. Proc Natl Acad Sci U S A 2006;103(48):18374-9. [PubMed: 17101963]

65. Fries JF. Aging, natural death, and the compression of morbidity. N Engl J Med 1980;303(3):130-5. [PubMed: 7383070] 


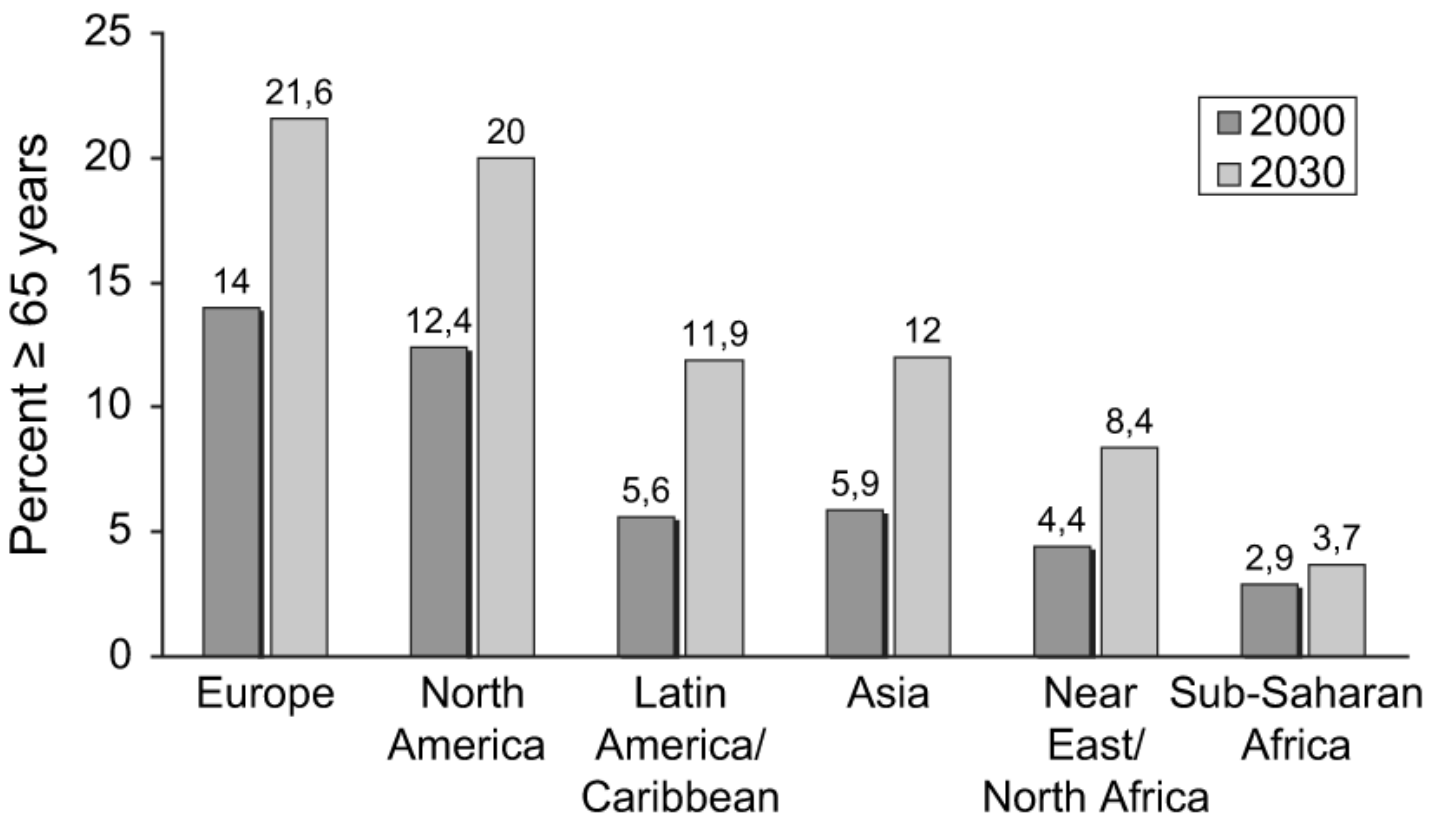

Fig. 1.

Population aging throughout the world. 


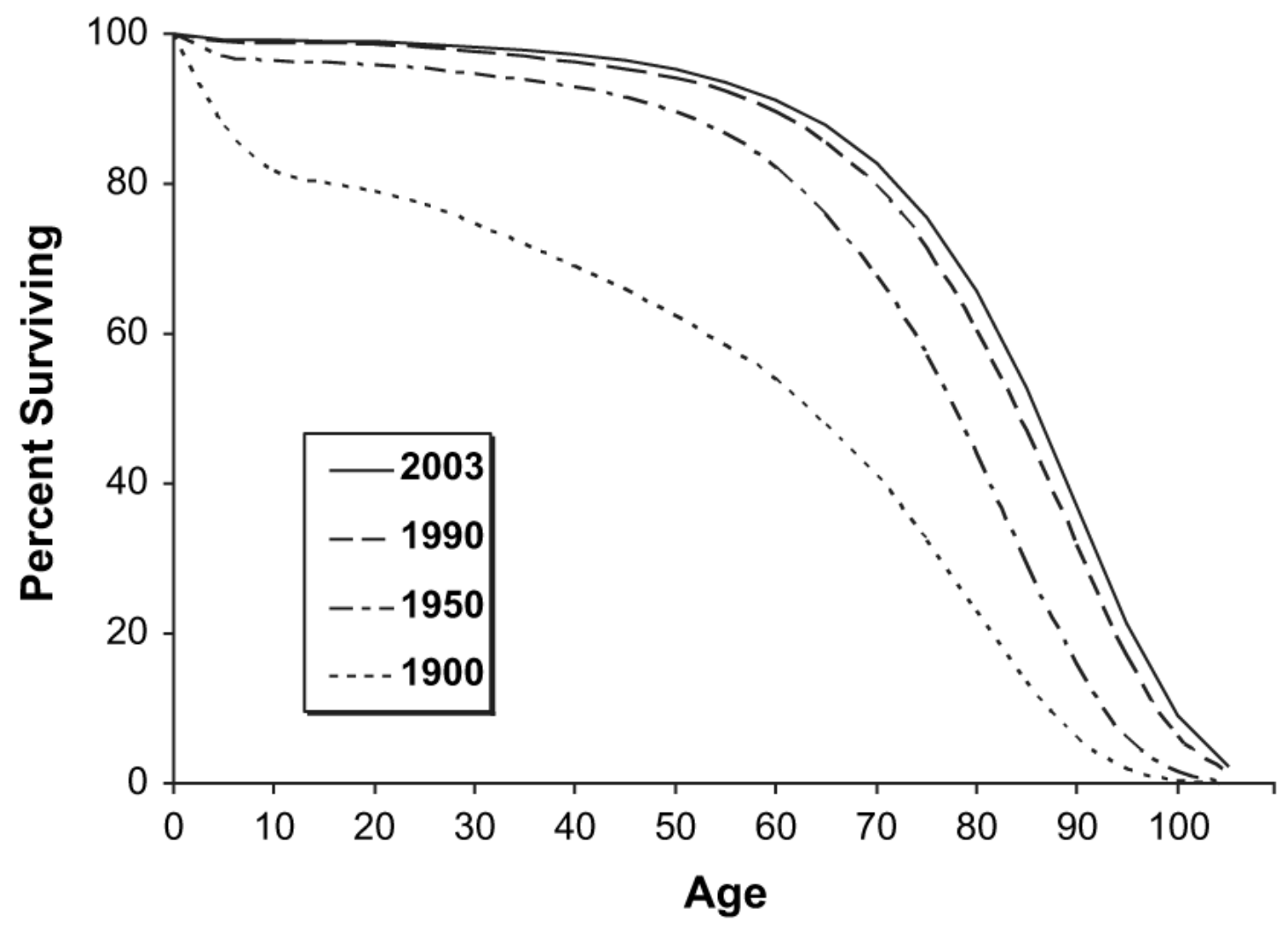

Fig. 2.

Survival curves of aging population. 


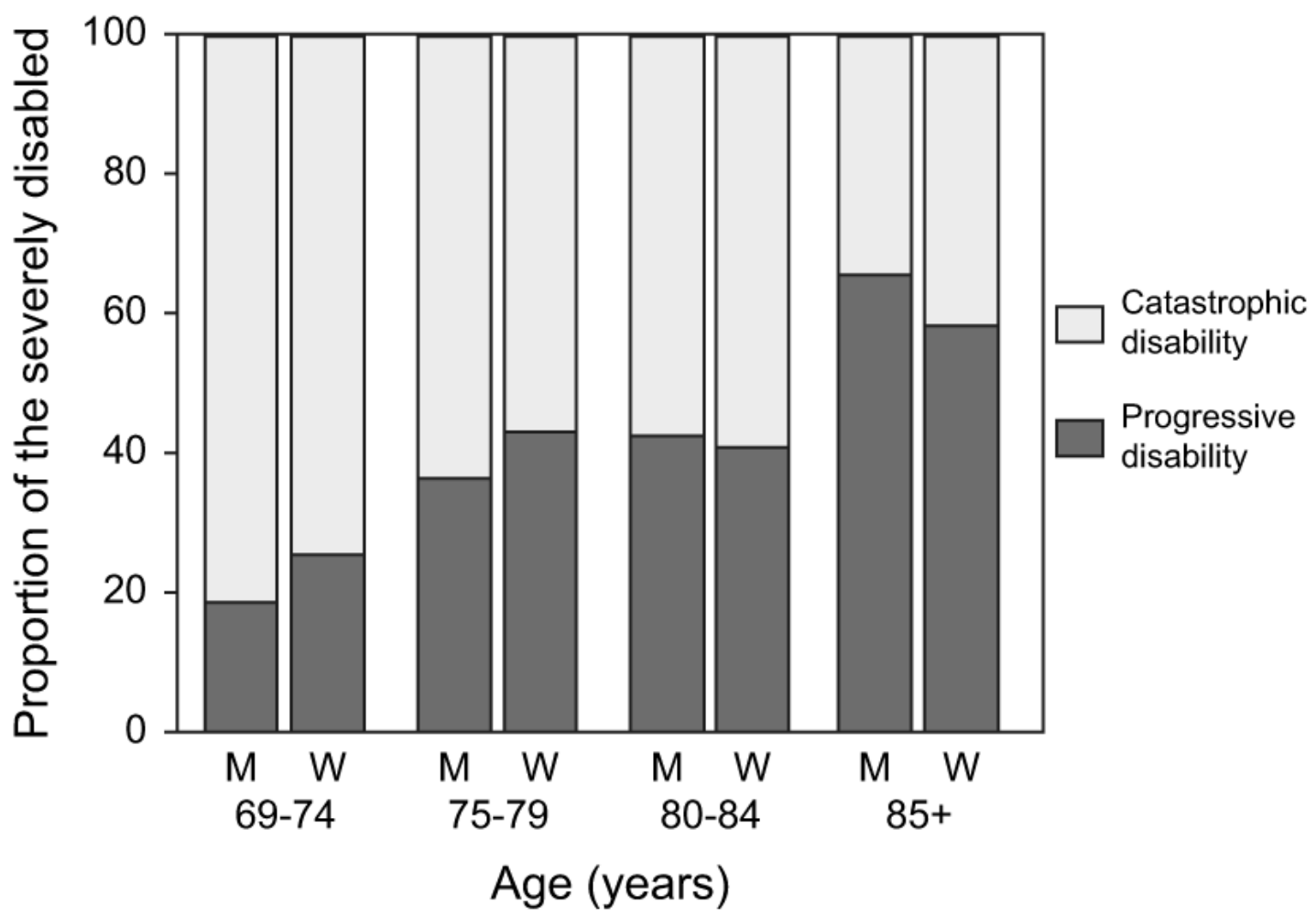

Fig. 3.

Proportion of "catastrophic" and "progressive" disability stratified by age. 


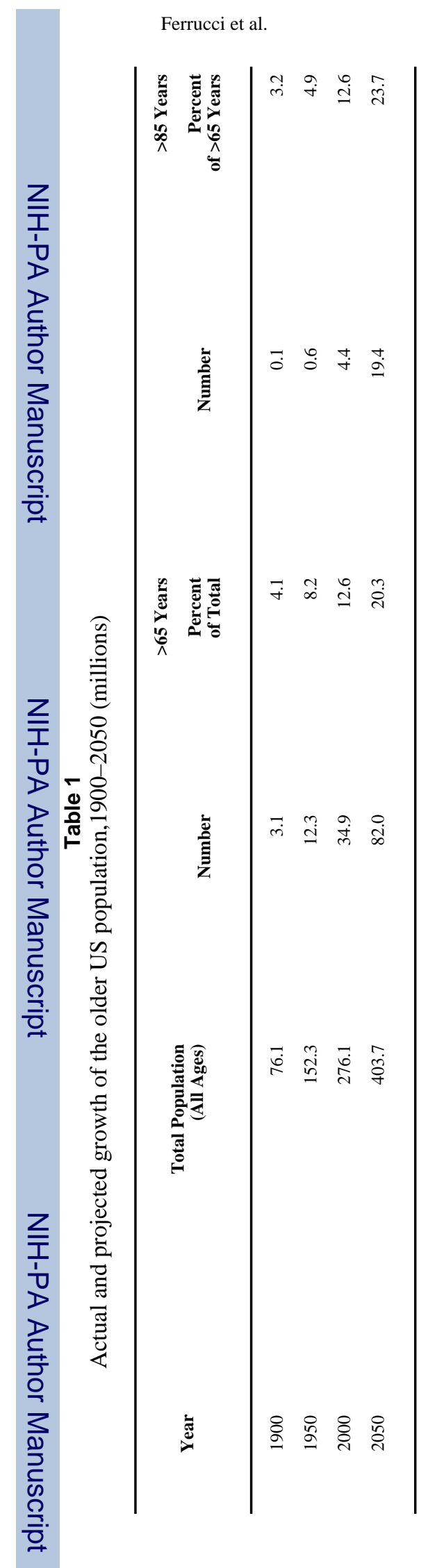

Page 14 


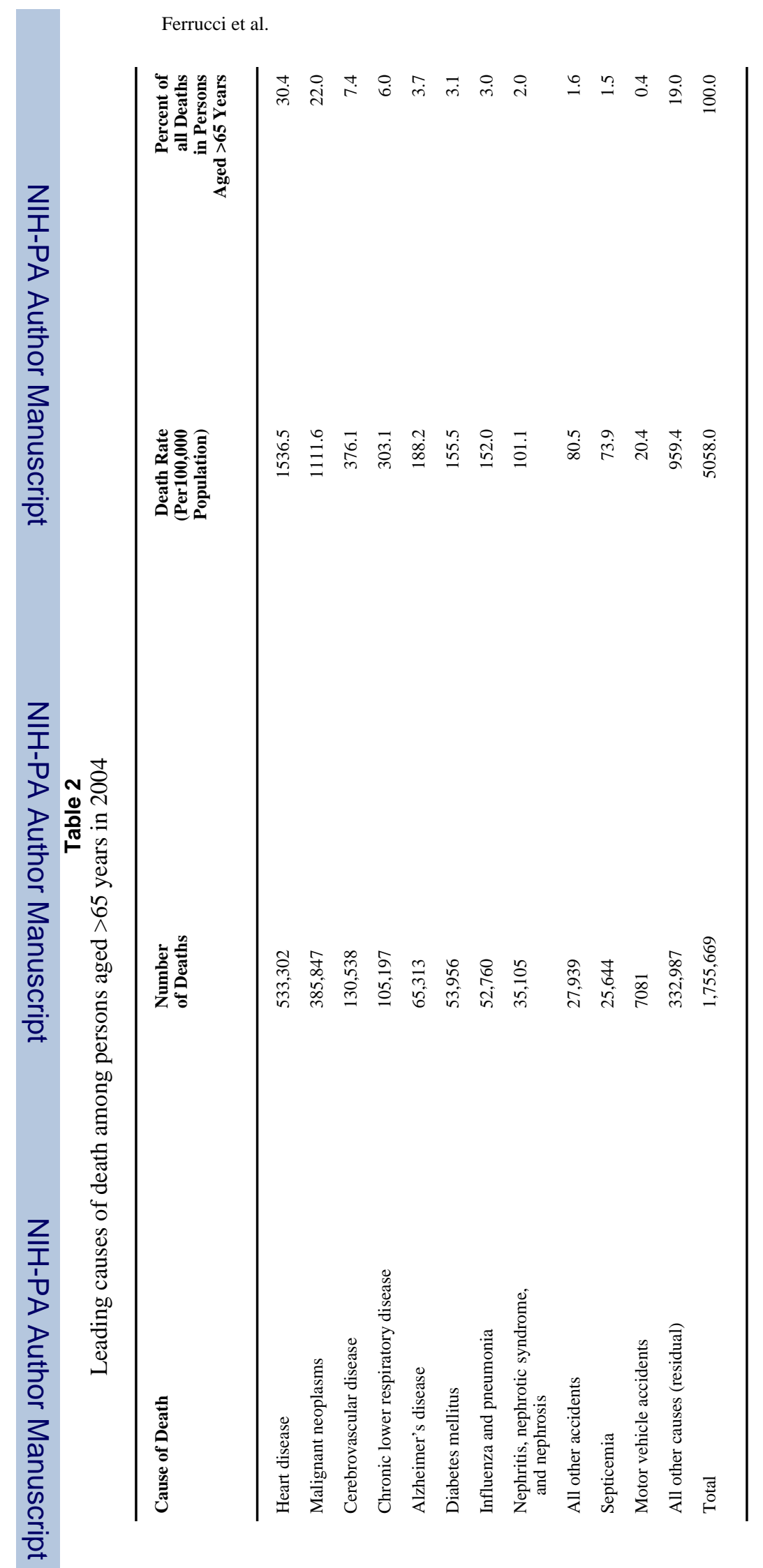

Radiol Clin North Am. Author manuscript; available in PMC 2009 July 1. 


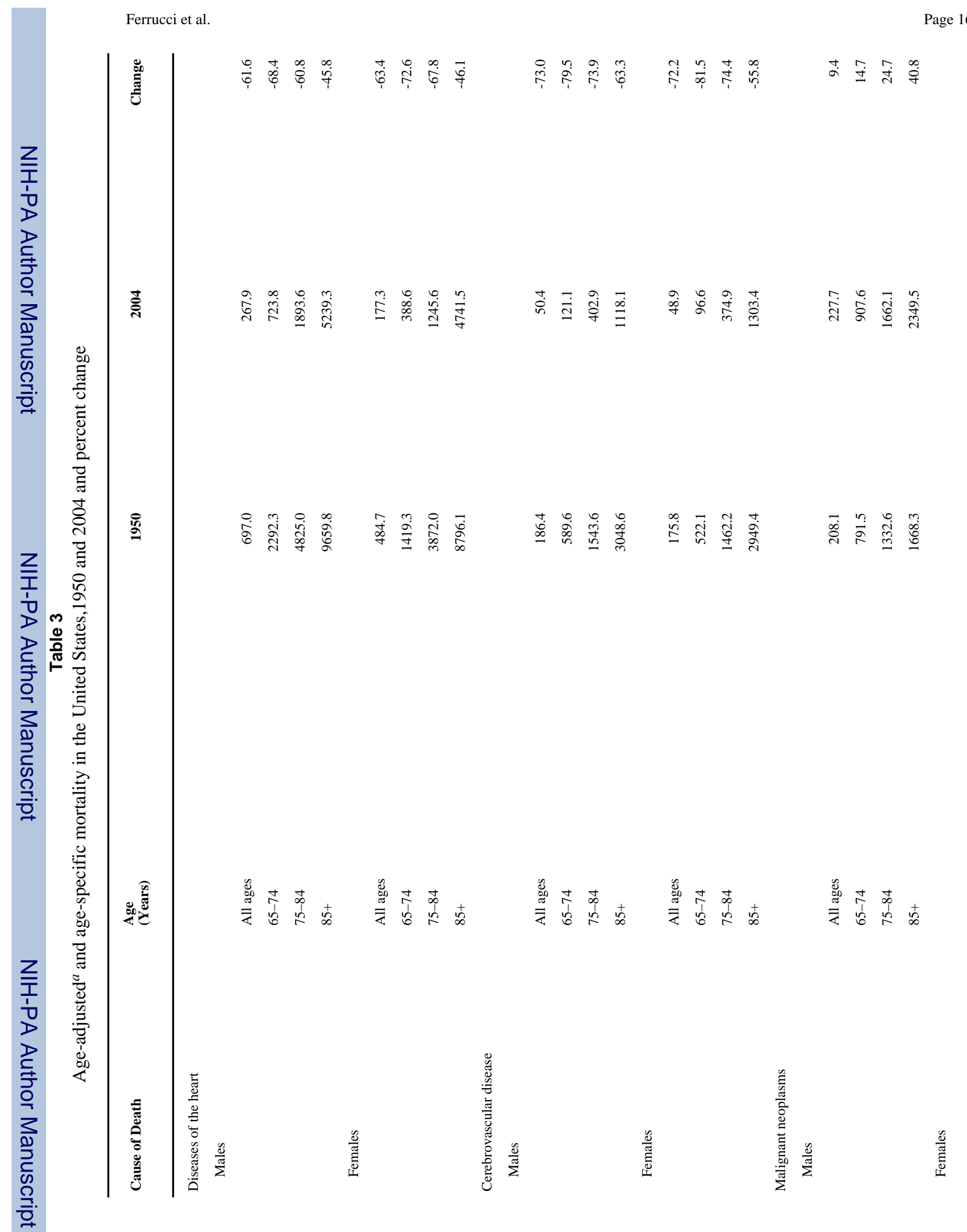

Radiol Clin North Am. Author manuscript; available in PMC 2009 July 1. 


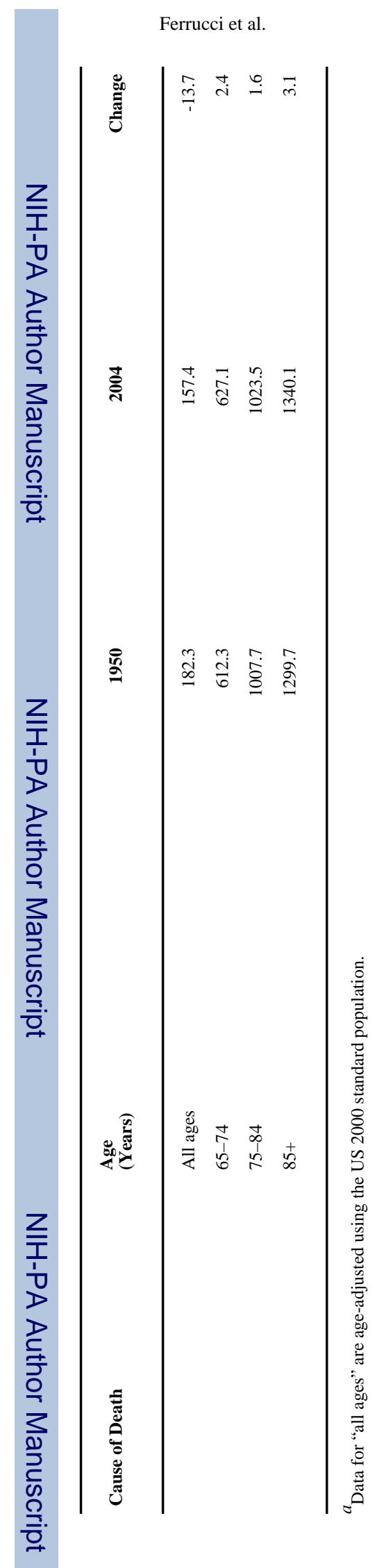

Page 17 
Table 4

Most commonly reported chronic conditions per 100 persons aged $>65$ years in 2005

\begin{tabular}{lcc}
\hline Condition & Men & Women \\
\hline Hypertension & 44.6 & 51.1 \\
Arthritis diagnosis & 40.4 & 51.4 \\
Chronic joint symptoms & 39.7 & 47.7 \\
Coronary heart disease & 24.3 & 16.5 \\
Cancer (any type) & 23.2 & 17.5 \\
Vision impairment & 14.9 & 18.7 \\
Diabetes & 16.9 & 14.7 \\
Sinusitis & 11.5 & 16.0 \\
Ulcers & 13.1 & 10.4 \\
Hearing impairment & 14.8 & 8.4 \\
Stroke & 8.9 & 8.2 \\
Emphysema & 6.3 & 4.1 \\
Chronic bronchitis & 4.5 & 6.3 \\
Kidney disorders & 4.1 & 3.9 \\
Liver disease & 1.4 & 1.4 \\
& & \\
\hline
\end{tabular}


Table 5

The ten leading causes of hospitalization in persons aged 65 years and older, first listed diagnosis in the United States, 2004

\begin{tabular}{lr}
\hline $\begin{array}{l}\text { Cause of } \\
\text { Hospitalization }\end{array}$ & $\begin{array}{r}\text { Discharge } \\
\text { Per 10,000 } \\
\text { Population }\end{array}$ \\
\hline Heart disease & 767.9 \\
$\quad$ Acute myocardial infarction & 126.6 \\
$\quad$ Coronary atherosclerosis & 158.6 \\
Cardiac dysrhythmias & 145.0 \\
$\quad$ Congestive heart failure & 225.0 \\
Pneumonia & 220.4 \\
Cerebrovascular disease & 175.6 \\
Malignant neoplasms & 172.2 \\
Fractures, all sites & 147.0 \\
$\quad$ Fractures, neck of femur & 79.6 \\
Osteoarthrosis and allied $\quad$ disorders & 117.7 \\
Chronic bronchitis & 88.9 \\
Septicemia & 78.5 \\
Volume depletion & 67.6 \\
Psychoses & 60.7 \\
\hline
\end{tabular}

